\title{
Medicina Estética em Portugal: Uma Complexa Equação, Onde Muitos Encontram a Resposta
}

\section{Aesthetic Medicine in Portugal: A Complex Equation, Where Many Find the Answer}

\author{
Diogo Cerejeira',2 \\ 'Serviço de Dermatologia. Hospital Garcia de Orta,, Almada, Portugal. \\ ${ }^{2}$ Mestrado Integrado em Medicina. Faculdade Ciências Médicas. Universidade Nova de Lisboa, Lisboa, Portugal.
}

PALAVRAS-CHAVE - Estética; Técnicas Cosméticas/complicações; Técnicas Cosméticas/legislação e jurisprudência. KEY WORDS - Cosmetic Techniques/complications; Cosmetic Techniques/legislation and jurisprudence; Esthetics.

\begin{abstract}
A medicina estética compreende todos os procedimentos médicos, invasivos ou não, que visam melhorar a aparência física e cosmética do doente. ' Apesar de não ser considerada uma sub-especialidade legítima, guiada por um programa curricular estruturado e universalmente aceite, era tradicionalmente vista como uma competência da Dermatologia e da Cirurgia Plástica e Reconstrutiva, pela proximidade da área de atuação.

Nas últimas duas décadas, impulsionada por campanhas de marketing agressivas com principal enfoque nos resultados e subestimando os riscos, esta área de diferenciação teve um crescimento exponencial e desmesurado, estimando-se em 20 milhões, o número de procedimentos realizados mundialmente a cada ano. ${ }^{2}$

Em Portugal a procura pela medicina estética não difere, observando-se uma popularidade crescente sobretudo dos procedimentos pouco invasivos, nomeadamente a injeção de toxina botulínica, preenchimentos, peelings químicos, transplantação capilar, laserterapia, luz pulsada intensa, radiofrequência e outras formas de rejuvenescimento incluindo microneedeling e mesoterapia. Tratando-se de técnicas utilizador-dependentes, o seu resultado depende de quem as pratica, ${ }^{3}$ podendo servir os doentes, mas também conduzir a danos irreversíveis, permanentes, na saúde e bem-estar. ${ }^{4}$ Entre as complicações descritas englobam-se algumas intercorrências simples, mas também a possibilidade de cicatriz, queimadura, ulceração, formação de granulomas, abcessos, erisipelas, oclusão vascular, necrose tecidular, paralisias musculares, desfiguração, cegueira e em última instância morte.
\end{abstract}

As entidades reguladoras e governamentais não conseguiram acompanhar a velocidade de crescimento desta indústria pelo que, apesar dos riscos inerentes, estes procedimentos estão quase inteiramente por regular. $O$ vazio legal permite assim, que qualquer pessoa exerça esta atividade, independentemente do seu conhecimento, treino ou experiência prévia. Qualquer pessoa pode ainda declarar-se expert em medicina estética, transmitindo a ideia de ser especificamente qualificada nesta área e equiparada formalmente a outros especialistas.

Apesar das normas de boa prática clínica sugerirem que cada médico deva agir dentro da sua competência e limites daquilo que a sua especialidade prevê, ${ }^{5}$ muitos têm visto nesse vazio legal um escape apelativo e simultaneamente recompensador quer em termos laborais, quer a nível financeiro. Provenientes das mais diversas áreas, geralmente sobrelotadas, encontram na medicina estética um mercado por explorar e, por enquanto, com capacidade para os acomodar. De forma mais gravosa, é ainda concedida a possibilidade de outros profissionais de saúde e até centros de estética ou salões de beleza levarem a cabo este tipo de procedimentos, incorrendo naquilo que serão os limites legais do exercício da medicina.

Na ausência de um ciclo de estudos estruturado desta sub-especialidade em Portugal ou de uma formação universalmente reconhecida e acreditada, que dê acesso a estas práticas, qualquer entidade pode providenciar um curso e atribuir competências a quem os frequente. Assim, para além dos workshops patrocinados pelas próprias empresas que detêm os produtos, as pós-graduações que
Correspondência: Diogo de Almeida Cerejeira Rua Marta Mesquita da Câmara, n 110 - A3 - $4^{\circ}$ Dto 4150-485 Porto - Portugal

E-mail: Diogo_cerejeira@hotmail.com

DOI: https://dx.doi.org/10.29021/spdv.77.3.1121
Aceite/Accepted 2019/09/11
Publicado/Published 2019/10/10 (c) Autor (es) (ou seu (s) empregador (es)) e Revista SPDV 2019. Reutilização permitida de acordo com CC BY-NC. Nenhuma reutilização comercial.

(C) Author(s) (or their employer(s)) and SPDV Journal 2019. Re-use permitted under CC BY-NC. No commercial re-use. 


\section{Editorial}

existem são em geral pouco seletivas e de duração insuficiente para assegurar uma prática correta e autónoma da medicina estética. Algumas universidades estrangeiras permitem ainda a frequência de pós-graduações em formato e-learning, com uma componente prática residual, que em nada corresponde aos desafios clínicos daqueles que exercem esta profissão.

Outra questão pertinente prende-se com o local onde estes procedimentos são executados. Não existindo pré-requisitos definidos, nem ações de fiscalização periódicas, muitas destas técnicas são realizadas em estabelecimentos não licenciados e sem as condições necessárias de esterilização e assépsia.

Na dependência destes factores, apesar de não existirem mecanismos formais de reportar complicações que permitam a criação de uma base de dados estatística nacional, tem-se verificado um incremento do número de reclamações, intercorrências e processos médico-legais decorrentes de tratamentos inadequados. Muitos destes casos acabam por ser referenciados e admitidos em hospitais do Serviço Nacional de Saúde (SNS), transferindo o ónus das entidades privadas para um SNS já sob uma grande pressão financeira.

De forma a equiparar Portugal a outros países europeus, (tais como Inglaterra, ${ }^{6}$ Dinamarca $^{7}$ e Suécia ${ }^{8}$ ), está por criar um conjunto de medidas que assegure a prática destes procedimentos por quem os domine, em locais certificados e com um sistema apropriado para dar resposta a eventuais complicações. Todos os que se queiram submeter a um procedimento cosmético devem ter o direito de o fazer numa clínica apropriadamente regulada, com produtos seguros e onde a discrepância de preço não seja fator decisivo. ${ }^{3}$

Torna-se imperativo combater um problema que tem vindo a ganhar uma dimensão crescente, pelo que se apela a governo, às entidades reguladoras e à ordem dos médicos para que a segurança das pessoas seja privilegiada em detrimento dos interesses comerciais.
Conflitos de interesse: Os autores declaram não possuir conflitos de interesse.

Suporte financeiro: $O$ presente trabalho não foi suportado por nenhum subsidio o bolsa ou bolsa.

Conflicts of interest: The authors have no conflicts of interest to declare.

Financial support: This work has not received any contribution grant or scholarship.

Proveniência e revisão por pares: Comissionado; sem revisão externa por pares.

Provenance and peer review: Commissioned; without externally peer reviewed.

\section{REFERÊNCIAS}

1. American Academy of Aesthetic Medicine. What is Aesthetic Medicine? 2019[consultado 2019 Fev 10]. Disponível em: https://www.aaamed.org.

2. International Society of Aesthetic Plastic Surgery. 2016 global statistics [consultado 2019 Fev 10]. Disponível em: https://www. isaps.org.

3. American Academy of Dermatology. Cosmetic treatment from unqualified providers may result in complications. 2018 [consultado 2019 Fev 10]. Disponível em: https:// www.aad.org.

4. Department of Health and Social Care, UK. Government Response to the Review of the Regulation of Cosmetic Interventions. 2013; [consultado 2019 Fev 10]. Disponível em: https://www.gov.uk.

5. General Medical Council. Good Medical Practice; c2019; [consultado 2019 Fev 10]. Disponível em: https://www. gmc-uk.org.

6. Health Education England, UK. Qualification requirements for delivery of cosmetic procedures. 2015 [consultado 2019 Fev 10]. Disponível em: https://www.hee.nhs. uk/sites/default/files/documents/HEE\%20Cosmetic\%20 publication\%20part\%20one.pdf.

7. National Board of Health, Denmark. Statutory Order regarding cosmetic treatments. 2007. [consultado 2019 Fev 10]. Disponível em: http://www.sst.dk.

8. Lakemedelsverket, Swedish Medical Products Agency. Cosmetic products. 2014 [consultado 2019 Fev 10]. Disponível em: https://lakemedelsverket.se/ 